\title{
Decisions and Strategies in a Sequential Search Experiment
}

\author{
by \\ Joep Sonnemans
}

\begin{abstract}
The strategy method is becoming an important tool in experimental methodology. This study examines how well this method works in an individual decision experiment. Subjects are faced with a sequential search problem. After extensive practice solving the problem and formulating strategies, they play 20 periods for money. In each period the subjects first make decisions by hand, and after that their strategy operates on the same sequence of bids. Each period only one of the results is paid out (randomly determined). After each period subjects can change their strategy. This method makes a direct comparison between strategies and decisions possible.
\end{abstract}

Keywords: Strategy method, Sequential search, experiment

JEL: C91, D83

December 1997

Address:

University of Amsterdam

Faculty of Economics and Econometrics

Department of Micro-economics/CREED

Roetersstr. 11

1018 WB Amsterdam

the Netherlands

tel. 31-205254249

fax. 31-205255283

e-mail: joeps@fee.uva.nl

* Financial support by the Netherlands' Organization for Scientific Research (NWO) is gratefully acknowledged. I am very thankful to John Hey, Theo Offerman, Frans van Dijk, Jörgen Wit, Claudia Keser and Tanga McDaniels for their help and comments. 


\section{$\S 1$ Introduction}

The strategy method is becoming a more and more popular tool in experimental economics (Selten, Mitzkewitz and Uhlich 1997, Brandts and Schram 1996, Sonnemans 1996, Mitzkewitz and Nagel 1993, Keser 1992; see also the classic work of Axelrod 1984). Subjects are asked to formulate a complete strategy, that is, a description of all their actions in all possible states of the world. After a state of the world occurs (as a result of actions by others or a random mechanism), the action prescribed by the strategy is carried out. The subjects are paid according to the performance of the strategy.

The strategy method has two main advantages: (1) it is a cheap way to gather many data and (2) the researcher may get a better idea of the reasoning behind the behavior of the subject. Because the subjects are paid according to the performance of the strategy they submit, they have an incentive to report honestly what they think is the best strategy. This is an important advantage of the strategy method over questionnaires. However, a very important question is whether these strategies indeed correctly describe the decisions the subjects would make when actually confronted with a state of the world ${ }^{1}$. A difference between strategies and decisions can be caused by the inability of some subjects to formulate their behavior in an admissible form of the strategy. For example, in most strategy-method experiments subjects are not allowed to include random mechanisms in their strategy, although they might normally act more or less impulsively. Differences can also be caused by subjects making mistakes if they have to make many repeated decisions (as is the case in many experiments), and they may avoid these mistakes in their strategy. Furthermore, a strategy is seen by some subjects as a kind of commitment. They formulate how they think they should act, although they know that normally they would sometimes deviate from this strategy (Sonnemans 1996).

Before economic experimentalists can really trust the strategy method, we need an evaluation of the method. To make a start, the present study compares decisions and strategies in a relatively simple individual decision making environment.

One possible experimental design to compare strategies with decisions is to let subjects make decisions in the first part of the experiment and formulate strategies in the second part. For each subject the researcher can compare the decisions in the first part with the actions the strategy would chose in the same states of the world (Sonnemans 1996). Although this method may give some idea about the usefulness of the strategy method, it has the disadvantage that the subject may have learned and changed his or her strategy during the experiment.

In this study an attempt is made to establish the correspondence between strategies and decisions of subjects in a different way. In a sequential search experiment, subjects first play some practice periods in which they make decisions and practice formulating strategies. Then they start the first period by formulating a strategy. In each period, subjects first make decisions, and then the strategy operates on the same state of the world (sequence of bids). Each period only one of the

\footnotetext{
1 In everyday life an individual may also use an explicit strategy to instruct an agent (e.g. a stock broker). In these instances strategies are interesting in their own right.
} 
results is paid out (randomly determined). After each period subjects can change their strategies. This method makes a direct comparison between strategies and decisions possible.

Section 2 describes the design of the study and section 3 discusses the results. Section 4 concludes.

\section{§ 2 Design}

In two sessions 31 subjects participated. Nobody had participated in previous search experiments. The subjects earned an average of 27.3 guilders in approximately 1 hour. The experiment was computerized. The computer program was made by the author in VISPRO-REXX for an OS/2 environment and is available from him.

\section{The search problem}

Subjects in the experiments are confronted with the following search problem (see the appendix for the precise instructions to the subjects). They receive an 'article' which they have to sell to the computer. The computer starts with an initial bid. The subject can accept this bid, or ask for another bid. The number of bids is unlimited and at any time the subject can decide to sell for the highest bid so far. Each bid costs 10 cents and is drawn from a discrete uniform distribution [1;500]. All bids are stochastically independent. There is a fixed cost per period of 250 cents.

A risk neutral decision maker will stop searching if the marginal cost of an additional search action ( $=10$ cents) exceeds its expected marginal benefit:

$$
.002 * \sum_{j=H+1}^{500}(j-H)=.001 *(500-H) *(501-H), \text { with } \mathrm{H} \text { the highest bid so far. }
$$

This means that search will continue until a bid greater than 400 cents is drawn (the reservation price). The expected earnings are 150.5 cents with a standard deviation of 53 cents.

\section{Strategies}

Subjects are asked to formulate strategies. For practical reasons the strategies have a specific format. This format was also used in another study (Sonnemans 1996) and is based upon the strategies subjects described in the questionnaire of a pilot study. In the Sonnemans (1996) study only 2 of 36 subjects wanted to submit a strategy which did not fit the format. This means that the possibilities offered to the subjects are not very restrictive. The strategy is a stopping criterion which consists of one stopping condition, or a combination of more conditions. The stopping conditions have the form:

I want to stop:

A. If the last bid is greater than or equal to:

B. If the highest bid is greater than or equal to:

C. If the number of bids is greater than or equal to:

D If my earnings are greater than or equal to:

E. If ..... bids in a row are smaller than the highest bid so far. 
The subject fills in numbers for the stopping condition(s) he or she wants to use, and formulates the stopping criterion " $\mathrm{X}$ " if only stopping condition $\mathrm{X}$ is to be used, or a logical combination of stopping conditions e.g. "X or $\mathrm{Y}$ ", or "X and $\mathrm{Y}$ ", or "(X or $\mathrm{Y})$ and $\mathrm{Z}$ ". After the subject has formulated a strategy, the program reformulates the stopping condition in words to check whether the strategy is really what the subject wants it to be (e.g. "stop if the last bid is greater or equal to 425 , or the number of bids is greater or equal to $6 ")$. If this is not what the subject meant, she can change her strategy. The program also warns subjects who formulate a strategy which may never stop (e.g. the strategy "stop if my earnings are greater than or equal to 200" stops after one of the first 5 bids or never).

\section{Procedure}

Subjects received instructions on paper. A translation of these instructions is included in the appendix. First the search problem was explained. Then they answered 3 questions to check understanding. The experimenter checked the answers to these questions and, if necessarily, answered questions. Subjects than practiced 20 periods in which they had to decide (by hand) whether they wanted another bid. Then they received instructions about formulating a strategy. The experimenter showed them how to input their strategy. They practiced 20 periods. They could change their strategy between periods. If there was some time left, they could also practice with the computer screen as used in the real experiment. After everybody finished the instructions and had a chance to practice with the computer screens, the experiment was started. Subjects could earn no money in the practice periods.

The experiment lasted 20 periods. Before the first period subjects formulate a strategy. In each period subjects first make decisions (ask as many bids as they like), and then their strategy operates on the same sequence of bids. In each period only one of the results is paid out (randomly determined). After each period subjects can change their strategy.

\section{§ 3 Results}

The practice periods are not analyzed, only the 20 'real' periods in which the subjects earned money ${ }^{2}$. The subjects had much opportunity to practice, and when they started the 20 experimental periods, they seemed pretty confident about their strategy. Of the 31 subjects, 20 did not change their strategy at all in these periods, 7 subjects did never change the form of the strategy but changed the numbers within the strategy ( 2 subjects did this once, 4 subjects twice and 1 subject three times), and only 4 subjects changed the form of their strategy (3 subjects changed once, one changed 3 times). Most subjects may have felt that there was not much room for improvement of their strategies. We will first look at the optimality of the subjects' decisions, then the kind of strategies subjects employed will be examined and finally, the correspondence between the strategies and the decisions will be studied .

\footnotetext{
2 Though the very first practice strategy the subjects submitted is of some interest. Twenty of the 31 subjects included earnings in this first attempt, and 5 of these subjects were warned by the computer that their strategy was not allowed because it possibly would never stop (e.g. the earnings are the only stopping condition in the criterion).
} 


\section{Optimality of decisions and strategies}

How well did the subjects do? Their earnings are on average 138.7 cents for decisions and 135.0 cents for strategies per period, this is respectively $92.2 \%$ and $89.7 \%$ of the earnings an optimal risk neutral strategy would earn on average (150.5 cents). The average number of bids is 4.93 (decisions) and 4.94 (strategy), while the risk neutral optimal strategy would ask 5 bids on average (see also table 4). Table 1 compares the stopping behavior in decisions and strategies with the optimal strategy. Stopping is optimal in 66\% (decisions by hand) and 69\% (strategies) of the cases, and strategies appear to stop more often early than late.

In the set-up of this experiment subjects can revert to an earlier bid (the earnings equal the highest bid minus the costs, and not the last bid minus the costs). However, the risk neutral optimal strategy will never revert to an earlier bid. In the experiment reversions to an earlier bid occurred in $16.5 \%$ (decisions by hand) and $15.8 \%$ (strategies) of the periods. Reversion in decisions by hand and strategies seems uncorrelated (table 2).

The results of this experiment are generally in line with the findings in other studies (Schotter et al 1981, Hey 1987, Cox et al 1989, 1991, Kogut 1990, Sonnemans 1996): search is highly efficient (in terms of earnings) and there is some tendency to recall. In many studies subjects tend to ask too few bids (compared with the risk neutral optimal strategy), e.g. Cox et al. (1989), Schotter et al. (1981). In this study the average number of bids is close to the average optimal number of bids; this may be caused by the extensive opportunity for practice.

Table 1: Stopping behavior compared with the risk neutral optimal strategy (the number of cases are displayed between brackets).

\begin{tabular}{l|ccc}
\hline & early & optimal & late \\
\hline Decisions by hand & $17.4 \%(108)$ & $65.7 \%(407)$ & $16.9 \%(105)$ \\
Strategies & $18.9 \%(117)$ & $68.5 \%(425)$ & $12.6 \%(78)$ \\
\hline
\end{tabular}

Table 2: Reversion to an earlier bid

\begin{tabular}{l|cc|c}
\hline & $\begin{array}{c}\text { Strategy } \\
\text { No reversion }\end{array}$ & $\begin{array}{c}\text { Strategy } \\
\text { Reversion }\end{array}$ & Total \\
\hline Decision by hand: No reversion & 457 & 61 & 518 \\
Decision by hand: Reversion & 65 & 37 & 102 \\
\hline Total & 522 & 98 & 620 \\
\hline
\end{tabular}




\section{Kinds of strategies used}

Table 3 shows a list of all strategies used by the subjects in the experiment. No subject indicated that he or she used a strategy which was impossible to formulate within the restrictions of the experiment. Only $8 \%$ of the strategies are reservation price strategies, and none is exactly optimal ${ }^{3}$. The number of bids is included in $68 \%$ of the strategies and the earnings are included in $74 \%$. The order of bids is included in $16 \%$ of the strategies (these percentages do not add to $100 \%$ because subjects can use combinations of conditions).

Table 3: Strategies used in the experiment. The number of subjects that used that strategy is mentioned between brackets.

\begin{tabular}{l|cc}
\hline Strategy & freq. & $\%$ \\
\hline Last bid & $20(1)$ & 3.2 \\
Highest bid & $13(1)$ & 2.1 \\
Last bid and Highest bid & $12(1)$ & 1.9 \\
Last bid or Highest bid & $7(1)$ & 1.1 \\
Last bid and Number of bids & $21(2)$ & 3.4 \\
Last bid or Earnings & $60(3)$ & 9.7 \\
Last bid or Number of bids or Earnings & $40(2)$ & 6.5 \\
(Last bid and Earnings) or Number of bids & $20(1)$ & 3.2 \\
(Last bid and Number of bids) or Highest bid or Earnings & $20(1)$ & 3.2 \\
Highest bid or Number of bids or Earnings or Order of bids & $61(4)$ & 9.8 \\
Highest bid or Number of bids or Earnings & $95(5)$ & 15.3 \\
Highest bid or Number of bids or Order of bids & $20(1)$ & 3.2 \\
Highest bid or Earnings & $24(2)$ & 3.9 \\
Highest bid or Number of bids & $60(3)$ & 9.7 \\
(Highest bid and Earnings) or Number of bids & $20(1)$ & 3.2 \\
Highest bid or Earnings or Order of bids & $40(2)$ & 6.5 \\
Highest bid and Number of bids & $7(1)$ & 1.1 \\
Highest bid or (Last bid and Earnings) & $20(1)$ & 3.2 \\
(Number of bids and Earnings) or Highest bid & $40(2)$ & 6.5 \\
Earnings or Number of bids & $620(31)$ & 100.0 \\
\hline Total & $20(1)$ & 3.2 \\
\hline & 20.5 \\
\hline
\end{tabular}

\footnotetext{
3 The first four strategies of table 3 are of the optimal form. However, note that the third and fourth strategy are formulated rather awkardly which shows that these subjects did not think in terms of reservation-prices.
} 


\section{Decisions and strategies compared}

The most interesting question is how well the strategies correspond with the decisions. During one period several decisions have to be made (after each bid the decision is to stop or not), the number of decisions depending on the number of bids. The decisions by hand equal the decisions by the strategy in $91.8 \%$ of the cases (see figure 1 ).

Another way to look at this, is to count the number of periods in which the strategy and the decisions by hand behave exactly the same (they stop after exactly the same bid). This happens in 402 periods of the 620 (65\%). When strategies and decisions do not coincide, the strategies-earnings are on average 10 cents less than the decision-earnings (table 4).

The next question is whether the differences between decisions and strategies is systematic, or only caused by small mistakes (noise). During the first 5 bids the strategies describe the decisions very well, but after that the strategies agree less often with the decisions (figure 1). Table 5 splits table 2 (about the incidence of reversion) into the periods where behavior and decisions by hand coincide or not. If the strategy and the decisions correspond, reversion to an earlier bid is rare (less than $3 \%$ ). In periods in which strategy and decisions do not coincide, reversion is very common: $42 \%$ of the decisions by hand and $40 \%$ of the strategies, and only in $30 \%$ no reversion occurred in both strategy and decision by hand. This suggests that disagreement between decisions and strategy is not only noise. Apparently many subjects want to stop (and revert to an earlier bid) if there they have already many bids, but that in those cases they don't have a clear strategy.

Table 4: Average earnings and number of bids when the strategy and the decision does and does not correspond.

\begin{tabular}{l|cccc}
\hline & $\begin{array}{c}\text { Average Earnings } \\
\text { Decision }\end{array}$ & $\begin{array}{c}\text { Average Earnings } \\
\text { Strategy }\end{array}$ & $\begin{array}{c}\text { Number of } \\
\text { Periods }\end{array}$ & $\begin{array}{c}\text { Average Number of } \\
\text { Bids } \\
\text { (Decision/Strategy) }\end{array}$ \\
\hline $\begin{array}{l}\text { Decision equals } \\
\text { strategy }\end{array}$ & $159.8 \mathrm{cent}$ & $159.8 \mathrm{cent}$ & 402 & 3.97 \\
$\begin{array}{l}\text { Decision differs } \\
\text { from strategy }\end{array}$ & $99.7 \mathrm{cent}$ & $89.2 \mathrm{cent}$ & 218 & $6.70 / 6.72$ \\
\hline Total & $138.7 \mathrm{cent}$ & $135.0 \mathrm{cent}$ & 620 & $4.93 / 4.94$ \\
\hline
\end{tabular}



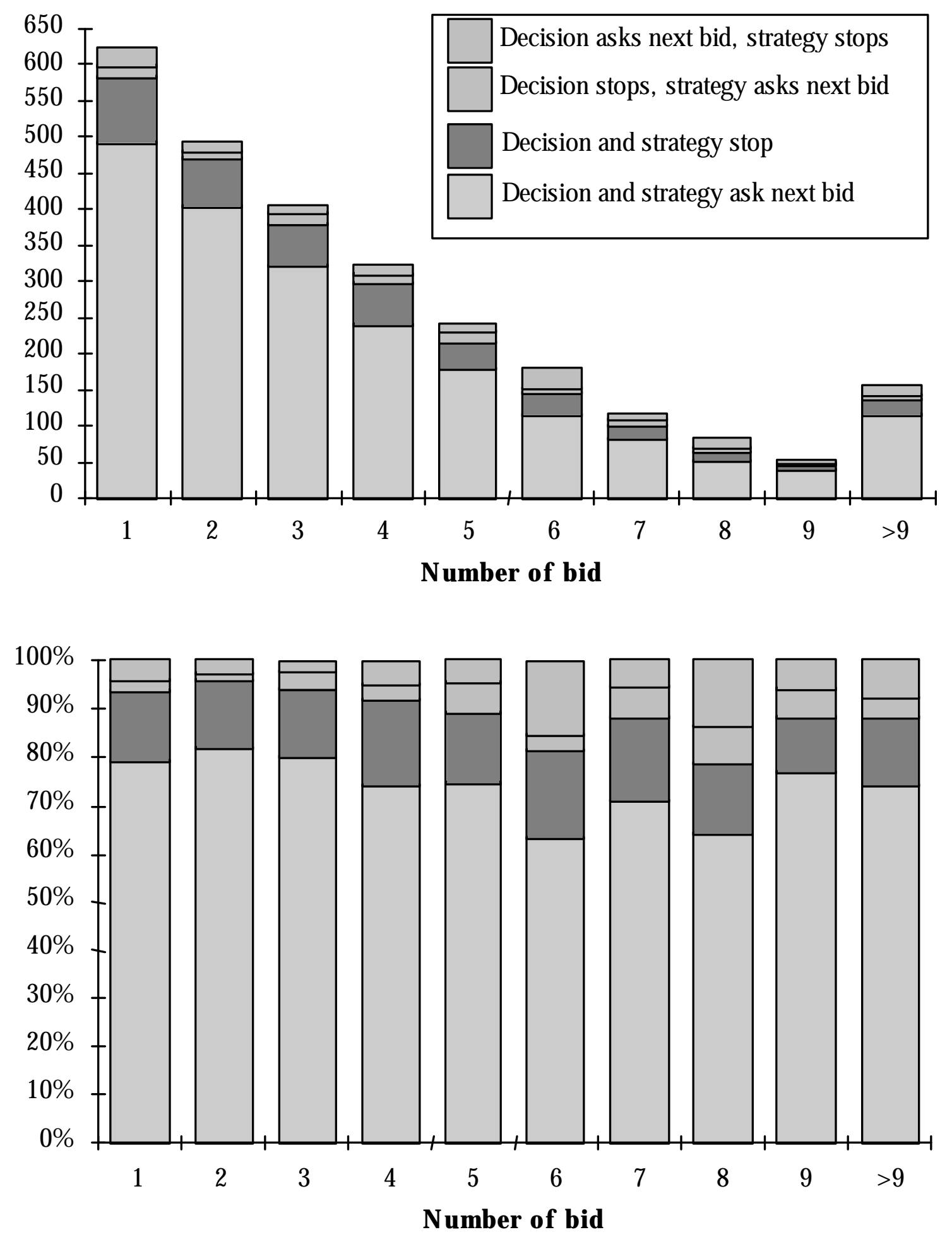

Figure 1a and 1b. Strategies and decisions by hand compared. The graph at top shows absolute numbers and the graph below percentages. 
Table 5: Reversion to an earlier bid by strategy and decision by hand, in the periods where strategy and decisions by hand do or do not coincide.

\begin{tabular}{|c|c|c|c|c|c|c|}
\hline & \multicolumn{3}{|c|}{ Decision equals strategy } & \multicolumn{3}{|c|}{ Decision does not equal strategy } \\
\hline & $\begin{array}{l}\text { strategy no } \\
\text { reversion }\end{array}$ & $\begin{array}{l}\text { strategy } \\
\text { reversion }\end{array}$ & total & $\begin{array}{l}\text { strategy no } \\
\text { reversion }\end{array}$ & $\begin{array}{l}\text { strategy } \\
\text { reversion }\end{array}$ & total \\
\hline $\begin{array}{l}\text { decision no } \\
\text { reversion }\end{array}$ & 391 & 0 & 391 & 66 & 61 & 127 \\
\hline $\begin{array}{l}\text { decision } \\
\text { reversion }\end{array}$ & 0 & 11 & 11 & 65 & 26 & 91 \\
\hline total & 391 & 11 & 402 & 131 & 87 & 218 \\
\hline
\end{tabular}

\section{Individual differences}

Six subjects formulated strategies which corresponded with all their decisions in at least 18 of the 20 periods (all periods for two subjects). Six other subjects did extremely bad; in less than $50 \%$ of the periods decisions and strategies coincided exactly. As described above, decisions and strategies disagree most often when subjects are confronted with a sequence of relatively low bids. Some subjects may have encountered more often these 'bad' sequences, which may partly explain the individual differences. To test this, I compare the number of periods in which decisions and strategies corresponded with a binomial $(0.65,20)$ distribution ${ }^{4}$, using a Kolmogorov - Smirnov goodness of fit test. The test yields a 2-tailed $\mathrm{p}$ of 0.056 , showing that substantial differences between subjects cannot completely be explained by some subjects being more (un)lucky with their series of bids than others. The conclusion is that the strategy method seems to work better with some subjects than with others.

\section{§ 4 Discussion and conclusion}

In this study the validity of the strategy method is examined in a specific environment: an individual sequential search experiment. The design enables to compare decisions and strategies.

The strategy method performed rather well: $92 \%$ of the decisions by hand are correctly described by the strategy. Because in a period a subject has to make many decisions (depending upon the number of bids), only in $65 \%$ of the periods the decisions by hand coincided completely with the strategy. The periods in which the decisions by hand did not coincide completely with the strategy were generally the 'bad sequences' in which the first 4 or 5 bids were low. For a rational risk-neutral subject the number of bids received shouldn't matter (the costs of these bids are sunkcosts), but for most subjects the number of bids did matter (the number of bids are included in $68 \%$ of the strategies). These subjects want to revert to an earlier bid if it takes too long before a high bid appears. When their strategy reverts to an earlier bid, only in $11.2 \%$ of the cases the decision reverts

${ }^{4}$ Remember that in $65 \%$ of all periods decision and strategy correspond. 
after the same bid (and in 26.5\% after another bid), and if the decision reverts, the strategy inverts in only $10.8 \%$ of the cases after the same bid (and in $25.5 \%$ after another bid) (see table 5). Reversion is rare in the cases when strategy and decision correspond. Apparently some subjects want to revert to an earlier bid in some situations, but they don't have a clear idea in which situations exactly, or they are not able to formulate their strategy correctly in this respect.

Some individual differences are observed. It is likely that the strategy method will work better in some populations of subjects (e.g. subjects with some practice in abstract reasoning) than in others.

There are two arguments why the strategy method would work better in an individual decision experiment than in an experiment with social interaction. (1) In some game-experiments subjects have to give their strategy for each possible role, before they get to know what their role is (e.g. divider or responder in an ultimatum game). This forces the subject to look at the situation from different viewpoints which may influence behavior (see Güth et al. 1990, 1997). (2) In games in extensive form or repeated games, emotions may play a more important role in decision making than in formulating strategies. For example, a subject may become angry because other player(s) made an unfair or stupid decision, and he or she may act impulsively. While formulating a strategy the same subject has to think about his/her action when this unfair situation occurs, but emotions will be of less importance because it is unlikely that the subject will become angry merely by the thought that the other player(s) may act unjustly.

These two possible problems of the strategy method in experiments with social interaction do not occur in individual decision making experiments. However, I don't think that the design of the present study is 'too nice' for the strategy method. In this sequential search experiment the set of possible states of the world for which a strategy has to be formulated is infinite $\left\{\left(\mathrm{x}_{1}, \ldots \mathrm{x}_{\mathrm{n}}\right) \mid \mathrm{x}_{\mathrm{i}}, \mathrm{n} \quad \mathrm{N}, \mathrm{x}_{\mathrm{i}}\right.$ $[1 ; 100]\}$ with $\mathrm{x}_{\mathrm{i}}$ a bid from the computer, while in most other experiments set of states of the world is limited. In the present study subjects could not make a list of all possible states of the world and indicate what they would do in that state. They had to use (a combination of) stopping conditions. This is of course a more abstract and probably for most subjects a more difficult procedure (however, note that the optimal strategy for a risk-neutral decision maker is very simple).

The strategy method has some important advantages and is becoming popular. What we need now are methodological studies about how the strategies correspond with decisions. This study focused on a specific individual decision making environment. We need similar studies on the use of the strategy method in environments with social interactions and games. 


\section{References}

Axelrod, R. (1984). The evolution of Cooperation. New York: Basic Books.

Brandts, J. and Schram, A. (1996). Cooperative gains or noise in public good experiments: applying the contribution function approach. Tinbergen Institute Discussion Paper TI 96-81/1.

Cox, J.C., \& Oaxaca, R.L. (1989). Laboratory experiments with a finite-horizon job-search model. Journal of Risk and Uncertainty 2, 301-330.

Cox, J.C., \& Oaxaca, R.L. (1992). Direct tests of the reservation wage property. The Economic Journal 102, 1423-1432.

Güth, W., \& Tietz, R. (1990). Ultimatum bargaining behavior. A survey and comparison of results. Journal of Economic Psychology 11, 417-449.

Güth, W., Ockenfels, P. \& Wendel, M. (1997). Cooperation based upon trust. An experimental investigation. Journal of Economic Psychology 18, 15-43.

Hey, J.D. (1987). Still searching. Journal of Economic Behavior and Organization 8, 137-144.

Keser, C. (1992). Experimental Duopoly Markets with Demand Inertia, Game-Playing Experiments and the Strategy Method. Heidelberg: Springer Verlag.

Kogut, C.A. (1990). Consumer search behavior and sunk costs. Journal of Economic Behavior and Organization 14, 381-392.

Mitzkewitz, M. \& Nagel, R. (1993). Experimental Results on Ultimatum Games with Incomplete Information. International Journal of Game Theory, 22(2), 171-98.

Schotter, A., \& Braunstein, Y.M. (1981). Economic search: an experimental study. Economic Inquiry 19, 1-25.

Selten, R., Mitzkewitz, M. \& Uhlich, G. R. (1997). Duopoly strategies programmed by experienced players. Econometrica 65, 517-555.

Sonnemans, J. (1996). Strategies of search. Forthcoming Journal of Economic Behavior and Organization. 


\section{Appendix}

These are the instructions of the experiment.

\section{General overview of the experiment}

1. Instructions. Some general things you have to know are explained.

2. You complete the exercises (page 3). The experimenter checks your answers before you can go on.

3. You practise 20 periods. In each period you have to decide (by hand) whether you want another bid. You cannot earn money in these practice periods.

4. Instructions about the formulation of a strategy.

5. You determine your first (practice) strategy (page 4). The experimenter will show you how to enter the strategy into the computer.

6. You practise 20 periods with the formulation of strategies (you enter the strategies into the computer yourself). You cannot earn money in these practice periods.

7. If there is time left you can practise working with the computerscreen that will be used in the experiment (you earn no money). see also page 5 .

8. When everybody has finished steps 1-6, the experiment starts. Your earnings in these 20 periods will be paid after the experiment. In each period you have to decide when to stop by hand. Your strategy will be applied to the same series of bids. In each period only one of these results will be paid, either the results of your decisions by hand, or the results of your strategy. The computer randomly decides which result will be paid (50\% probability for each possibility). After each period you can adapt your strategy.

In this experiment you get many opportunities to practise.Reading the instructions carefully and concentrated practising will allow you to get a good result in the last part of the experiment (when your results are paid out).

Please read now the instructions on the following pages. 


\section{Instructions}

You are participating in an experiment about decision making.

The experiment consists of several periods. At the start of each period you will get an article, you can sell this article to the computer. The computer will make as many bids as you like, and during any moment you can decide to sell the article for the highest bid the computer made so far that period.

Three things are very important to know:

1. In each period you have fixed costs of 250 cents (you can interpret this as the cost of the article). In addition every bid costs 10 cents. So your COSTS in a period equal (number of bids in that period)*10 cents +250 cents.

2. Your EARNINGS in a period equal the HIGHEST BID on the moment you stop, MINUS YOUR COSTS in that period.

3. All bids are integers between and including 1 and 500. Each of these integers is equally likely, and independent of previous bids.

It is possible to have negative earnings in a period (when on the moment of stopping the costs are higher than the highest bid). If this happens, you will lose money that period and that loss will be deducted from the earnings in other periods.

Your total earnings will be paid to you immediately after the experiment has ended, personally, confidentially and in cash. Your earnings are your own concern, you don't have to talk to anybody about it.

\section{Decision making by hand: the computer screen}

After each bid you have to decide whether you want another bid. You decide by clicking the mouse on one of the red buttons 'Another bid' or 'Stop'. If you are not used to a mouse, you can also use the keyboard and press 'a' for another bid or 's' to stop.

\section{Information}

At the top of the screen you see the series of bids that you have received this period. Below that you find summarizing information: the number of bids so far in this period, about the last bid you received, about the highest bid so far, about the costs of the bids so far and about what your earnings would be if you would stop at that moment. We will give an example:

\section{EXAMPLE}

Somebody received so far the bids $322,266,254$ and 168 . In that case the available information is:

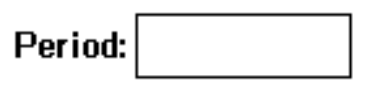

Bids:

322266254168

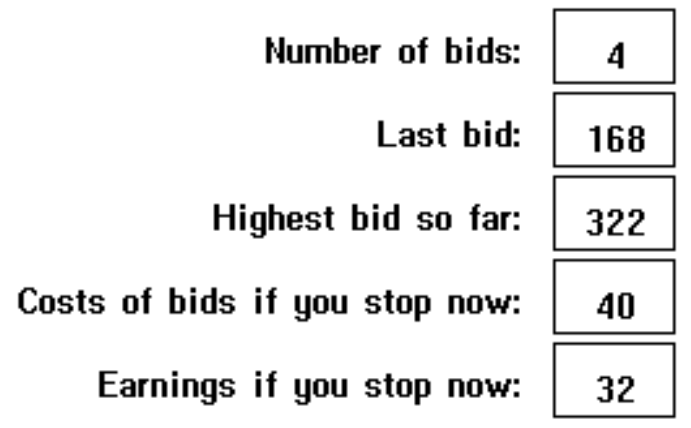

Cost of bids if you stop now=number of bids (4) times 10 cents $=40$ cents

Earnings if you stop now=highest bid (322) minus the fixed costs $(250)$ minus costs of the bids $(40)=322-250-40=32$ cents

Do now the exercises on the next page. 


\section{Exercises to check understanding of the instructions (on paper)}

Before we start with some practice periods, we want to check whether you understand the instructions.

If you have a question, please raise your hand. The experimenter will come to your table.

\section{Exercise 1.}

If the last 4 bids were all under 250 cents, what is then the probability that the next bid will be greater than 250 ?
a. less than $50 \%$
b. exactly $50 \%$
c. more than $50 \%$

Exercise 2

Someone has received successively the bids 114, 211, 17, 325 and 252. Fill out the schema below for this case.

$$
\begin{array}{r}
\text { Number of bids } \\
\text { Last bid } \\
\text { Highest bid so far } \\
\text { Costs of bids if you stop now } \\
\text { Earnings if you stop now }
\end{array}
$$

\section{Exercise 3}

Someone has received successively the bids 383, 168 and 342. Fill out the schema below for this case.

$\begin{array}{rr}\text { Number of bids } & \ldots \ldots . \\ \text { Last bid } & \ldots \ldots . \\ \text { Highest bid so far } & \ldots \ldots . \\ \text { Costs of bids if you stop now } & \ldots \ldots . \\ \text { Earnings if you stop now } & \ldots \ldots .\end{array}$

After you have finished these 3 exercises, raise your hand.The experimenter will come to your table to check your answers. Then the practice periods (deciding by hand) will start. 


\section{Instruction: formulating a strategy}

In this part of the experiment we ask you to formulate a strategy. The computer will use this strategy to make the decisions. Before a period starts you can change your strategy. To be sure that everybody understands this part of the experiment, the experimenter will type in your first strategy. After that you can change your strategy by yourself.

The situation is the same as before:

- The costs in a period equal 250 cents plus the number of bids multiplied with 10 cents;

- The earnings equal the highest bid on the moment of stopping, minus the costs;

- All bids are integers between and including 1 and 500. Each of these integers are equally likely, and independent of previous bids.

A strategy consists of a stopping criterion; this criterion consists of one or combination of more of the following stopping conditions:

I want to stop:

A. If the last bid is greater than or equal to: ......

B. If the highest bid is greater than or equal to:

C. If the number of bids is greater than or equal to:

D If my earnings are greater than or equal to: .......

E. If ..... bids in a row are smaller than the highest bid so far.

\section{Stopping criterion:}

If the your stopping criterion depends on one of the stopping conditions A, B, C, D or E, you fill in a value after that condition and you put that letter after 'Stopping criterion'.

It is also possible to make a stopping criterion which is a combination of stopping conditions. In that case you fill in the values for the conditions you want to use, and you use the words and or or to form the stopping criterion.

For example, if you want to stop if both conditions A and B are fulfilled, you use the criterion 'A and B'. At the other hand, if you want to stop if one of the conditions A or B is fulfilled, you use the criterion 'A or B'.

It is also possible to make a criterion which combines more than two conditions. In that case you may need to use brackets, for example '(A or B) and C' or 'A or (B and C)' (Note that these are different criteria).

Examples given are completely arbitrary and do not indicate what kind of strategy will result in a large profit.

If you want to use a strategy which cannot be formulated with the 5 conditions above, please ask the experimenter. If something is not totally clear, please raise your hand.

You can now fill in your first strategy. Raise your hand when you are ready. The experimenter will put the strategy into your computer. After that you can practice 20 periods with strategies (you musttype in the strategies by yourself). 
The real experiment: the computer screen

\section{Next period?}

Your strategy is:

(your present strategy is displayed here)

Change strategy

Next Period

You can change your strategy before the start of each period. After you have changed your strategy or have decided to keep it the same, you press "Next period". Then you decide by hand when to stop. After you have stopped, the computer will use your strategy on the same series of bids. In the lower part of the screen you see the results of your decisions by hand and those of your strategy. In each period only one of these results will be paid out. Which result will be paid is decided randomly by the computer (50\% probability each). The result which will be paid is indicated with an arrow behind the earnings $(<==)$

\section{CREED experiment}

Stop practice periods

Period: PRACT. 8

Bids:

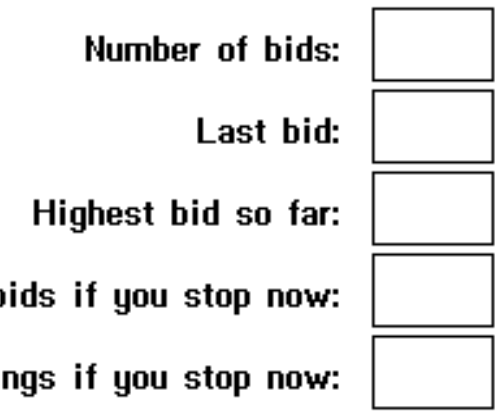

\section{First bid}

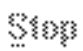

Costs of bids if you stop now:

Earnings if you stop now:
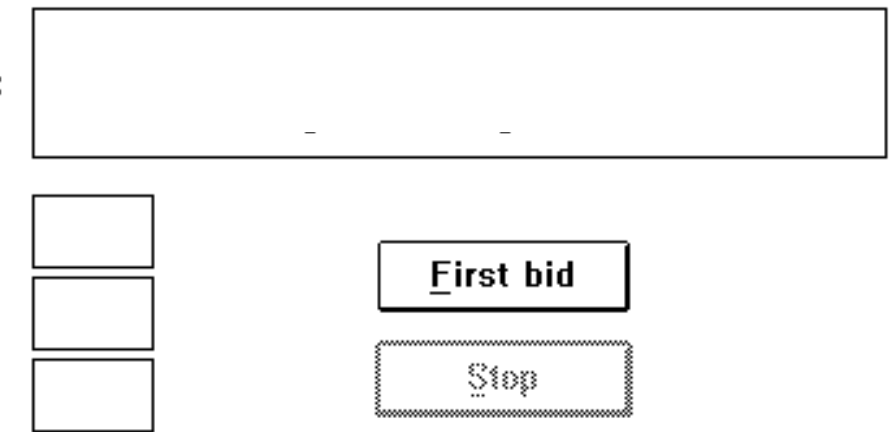

Total earnings so far 1064

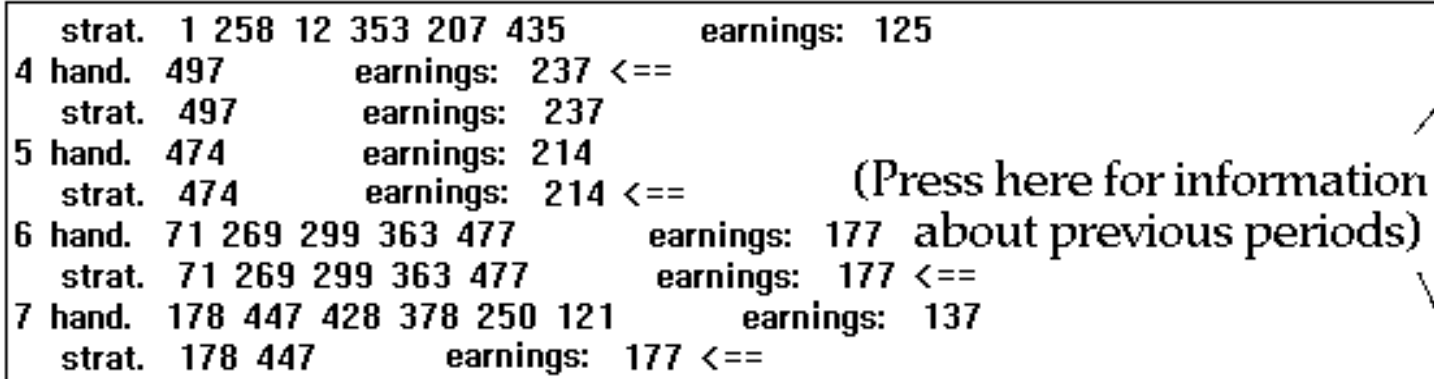

strat. 178947

(17)

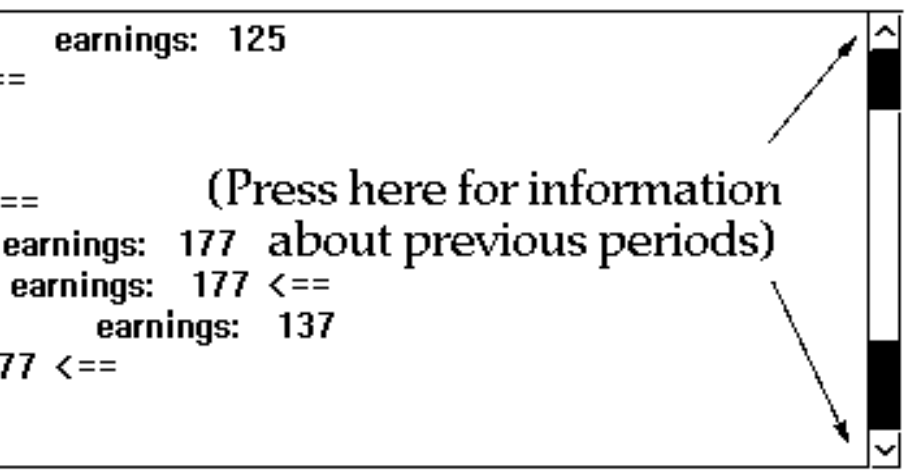

